\title{
Short-Term Outcome of CABG with Aortic Valve Replacement-A Single Center Study
}

\author{
Chowdhury MG ${ }^{1 *}$, Hoque $\mathrm{KZ}^{2}$, Hossain $\mathrm{M}^{3}$, BaraiLC ${ }^{4}$, Saha $\mathrm{MK}^{5}$, Jamil AM ${ }^{6}$ \\ ${ }^{1}$ Assistant Professor and Unit Chief, Pediatric Cardiac Surgery unit-3, Dhaka shishu (Children) Hospital, \\ Bangladesh \\ ${ }^{2}$ Assistant Professor and Unit Chief, Pediatric Cardiac Surgery unit-2, Dhaka shishu (Children) Hospital, \\ Bangladesh \\ ${ }^{3}$ Associate Professor, Pediatric Cardiac Anesthesia, Dhaka shishu (Children) Hospital, Bangladesh \\ ${ }^{4}$ Assistant Professor, Cardiology, MBBS, D.CARD, MCPS, National Institute of Cardiovascular Diseases and \\ Hospital, Dhaka, Bangladesh \\ ${ }^{5}$ Associate Professor, Unit Chief, Department of Orthopaedic Surgery, MBBS, D-Ortho, MS-Ortho, \\ Mymensingh Medical College, Mymensingh, Bangladesh \\ ${ }^{6}$ Assistant Professor (Medicine), Rajshahi Medical College, Rajshahi, Bangladesh
}

*Corresponding Author: Chowdhury MG, Assistant Professor and Unit Chief, Pediatric Cardiac Surgery unit-3, Dhaka shishu (Children) Hospital, Bangladesh

\begin{abstract}
Introduction: Myocardial ischemia is often associated to aortic valve stenosis in the elderly. Aim of this study was to evaluate the impact of CABG associated to aortic valve replacement on survival and quality of life in the old age group.
\end{abstract}

Objective: To find out short-term outcome of $C A B G$ with aortic valve replacement Cardiac operations in elderly patients.

Methods and Materials: The clinical data pertaining to patients undergoing cardiac surgery at Labaid Cardiac Hospital, Dhaka, Bangladesh from July 2016 to June 2018 (2 years) observation and follow-up 3 months included in an electronic database at the time of discharge. 52 patients ageing 50 years and above underwent aortic valve replacement with a mechanical prosthesis in Labaid Cardiac Hospital, Dhaka, Bangladesh. They were divided into 2 groups: Group A included 30 patients undergoing isolated aortic valve replacement; Group B included 22 patients receiving aortic valve replacement and CABG. A comparative analysis of short-termoutcome and quality of life was performed. Results: Mean age was $54.2 \pm 2.6$ years (54.3 \pm 2.6 in Group A, $54 \pm 2.3$ in Group B; $p=0.22)$. Study population was composed of 52 patients who underwent AVR for aortic valve stenosis. Among them, 22 patients (42.30\%) received associated CABG to $A V R$ (group $B)$, while 30 patients (57.70\%) received mechanical valve implantation in aortic position (group A). Mean cross clamp time was 148.9 min and mean CPB was $187 \mathrm{~min}$, The overall mortality rate was $7.6 \%$ (4 patients group $A \& B$ ), one of them could not be weaned from the bypass, the second one was CVA that required prolonged respiratory support, the third one was cardiac tamponade, and the last one was multiorgan failureMultivariate analysis did not reveal associated CABG as a predictor of short term mortality. The scores obtained in the SF-36 test were similar in the two groups and significantly higher than those of the general population matched for country, age and sex ( $p<0.001$ in all domains). Conclusion: Survivors did not show differences in short-term outcome and quality of life. Overall, the risk factors for short-term mortality following valve replacement and $C A B G$ surgery appear to be relatively consistent. However, clinicians should be aware of the importance of preoperative functional status as a unique predictor of mortality following valve surgery.

Keywords: Heart Valve Replacement, Mechanical Prostheses, Elderly, Quality Of Life, CABG.

\section{INTRODUCTION}

Driven by the increasing age of both the general population and the population of patients affected by heart disease, and by the progress of intraoperative and postoperative care, cardiac operations in the older age group are nowadays a clinical reality. Coronary artery disease is the 
most common cardiovascular disease and it is the major cause of death in the middle aged and older people in the most developing countries. In south Asian region, increased prevalence and excess mortality in coronary artery disease is reported by several studies. Moreover, this disease starts at young age with more aggressive presentation. Aortic valve replacement (AVR) is an accepted therapy for aortic valve disease [1]. It has been demonstrated that isolated AVR can be performed with a low perioperative mortality rate in elderly patients, improves short-term survival and quality of life (QOL) [2]. Calcified aortic stenosis is often associated with coronary artery disease and CABG is required during the AVR procedure. Aim of the present study was to investigate the impact of CABG plus AVR on short term outcome and quality of life in elderly patients. Bangladesh ranks $25^{\text {th }}$ position in the world in respect to cause of death due to coronary artery disease.[21]There is agreement that (1) cardiac operations in the old age group are feasible, although at the price of increased operative mortality and morbidity than in younger candidates[22, 23] (2) nonselective priority represents a major determinant of poorer outcome [22, 24] (3) when coronary disease accompanies valve disease, the prognosis is significantly ameliorated if concomitant coronary artery bypass graft (CABG) surgery is done, as in the younger candidates, [25] and (4) acceptable 5-year survival and quality of life have been reported in limited series.[25]However, uncertainty remains as to the prognostic gain of combined coronary and valve surgery. Data from the US National Cardiovascular database, which took into analysis 4743 cases, confirmed the concept that in selected octogenarians the operative mortality is similar to that observed in younger surgical candidate. [26] Such analysis provided only immediate results whereas follow-up data were not available, and patients undergoing surgical procedures on the thoracic aorta had been excluded. The finding of optimal results of cardiac surgery in these elderly candidates, who may be considered to have excessive operative risk, should prompt a reflection over the potential for the application of the percutaneous valve technologies currently under development. This congenital anomaly happens in as many as $1 \%$ of the total population and is the second most common a etiology of aortic stenosis [27]. Despite evidence supporting pharmacological management, valve replacement is the only definitive treatment to date. This explore aortic stenosis interventions with focus on the options available to the younger populations and developments in related modalities, provide evidence in support of these treatments, and highlight a few unanswered questions in related fields. Thus, the currently available data should be updated in the light of the more compound population of elderly individual's now subjected to cardiac surgery.

\subsection{Objective}

To find out short-term outcome of CABG with aortic valve replacement Cardiac operations in elderly patients.

\section{METHODS AND MATERIALS}

The clinical data pertaining to all patients undergoing cardiac surgery in the Labaid Cardiac Hospital, Dhaka, Bangladesh from July 2016 to June 2018 observation and follow-up 3 months included in an electronic database at the time of discharge. 52 patients ageing 50 years and above underwent aortic valve replacement in Labaid Cardiac Hospital, Dhaka, Bangladesh. They were divided into 2 groups: Group A included 30 patients undergoing isolated aortic valve replacement; Group B included 22 patients receiving aortic valve replacement and CABG. A comparative analysis of Short-term survival and quality of life was performed. The study population: Group A (30 isolated AVR) and Group B (22 CABG associated to AVR).

\subsection{In-Hospital Management}

All patients underwent preoperative full cardiac screening including trans-thoracic echocardiography and coronary angiography. All operations were performed by the same group of surgeons. Cardiopulmonary bypass methods were uniform throughout the study: systemic moderate hypothermia was employed in all cases, along with myocardial protection through crystalloid cardioplegia infusion into the aortic root in case of normal aortic valve competence, or directly into the coronary ostia in case of aortic valve regurgitation, associated to topical cooling with cold saline. Postoperative anticoagulant therapy was performed with oral warfarin in all patients, and INR was routinely checked during the postoperative hospital stay period, then weekly through the first postoperative month, and subsequently on indication of our dedicated anticoagulation outpatient clinic (by default once every three or four weeks). For patients with bileaflet mechanical prostheses in aortic position the warfarin was continued postoperatively with dose maintain target INR 2. 


\subsection{Follow-up}

The method of follow-up for our prospective study, in patient's mechanical valve replacement. Follow-up has mainly been conducted on all hospital survivors during our institutional ambulatory activities and was 98.3\% complete. Adverse events, with particular focus on bleeding, transient ischemic attacks, reversible or nonreversible ischemic neurologic deficits, are classified following the Guidelines for Reporting Morbidity and Mortality after Cardiac Valvular Operations as proposed by the Society of Thoracic Surgeons [6]. Monthly follow-up included an echocardiogram in addition to physical examination. To the purpose of the present analysis, data regarding the operation and the early postoperative period were prospectively collected by hospital charts and outpatient charts review, the anticoagulation results, the data regarding every complication possibly occurred and the scores obtained at the SF-36 test for each patient were prospectively inserted in an electronic database. INR variability (percentage of values outside the therapeutic range) was calculated for each patient.

\subsection{Quality of Life Assessment}

Follow-up included the assessment of perceived QOL through the SF-36 [7], which has an established validity and reliability [8]. The SF36 questionnaire consists of 36 items grouped into eight domains:

- Physical Functioning (10 items) indicates level of limitations in lifting, bending, kneeling, or walking moderate distance.

- Role-physical (4 items) measures the degree in performing of usual activities for age and social status, such as job and community activities.

- Bodily Pain (2 items) represents the intensity, frequency, and duration of bodily pain and limitations in normal activities due to pain.

- General Health (6 items) is a measurement of perceived overall health, including past and present health.

- Vitality (4 items) measures feeling of energy, fatigue, and tiredness.

- Social Functioning (2 items) indicates ability to develop and maintain mature social relationships.
- Role-emotional (3 items) measures personal feeling of job performance at work or other activities.

- Mental Health (5 items) measures the emotional, cognitive, and intellectual status of the patient.

- All SF-36 domains are scaled from 0 to 100 points, with higher scores indicating betterperceived QOL. The mean scores obtained by the two study groups were compared with those of the general Bangladeshi population matched for age and sex.

\subsection{Statistical Analysis}

Continuous data were expressed as mean $\pm \mathrm{SD}$, and compared using Student's t test. Discrete variables were compared using the chi-square test. Factors significantly associated with adverse outcomes were introduced in a multivariate logistic regression model to identify independent predictors of hospital and shortterm mortality. Kaplan-Meier actuarial analyses of survival rates and of freedom from valverelated complications were performed. Scores obtained in each of the 8 domains of the SF-36 test were compared with those reported for the age and sex-matched Bangladeshi population. Kaplan-Meier actuarial analyses of survival rates and incidence of valve-related complications were performed. Actuarial rates are expressed as percentage of patients who were event free. Continuous data are reported as mean \pm SD. A difference yielding a $\mathrm{p}$ value of $<$ 0.05 was considered statistically significant. SPSS statistical software, version 21.0 was employed for analysis.

\section{ReSUlts}

Preoperative characteristics of the study population are reported in [Table 1]. Study population was composed by 52 patients who underwent AVR for aortic valve stenosis. Of them $22(42.30 \%)$ patients received associated CABG to AVR (group B), while $30(57.70 \%$ ) received isolated mechanical valve implantation in aortic position (group A). All patients were older than 50 years with a mean age of $54.2 \pm$ $2.6,54.3 \pm 2.6$ in group A versus $54 \pm 2.3$ in group $\mathrm{B}(\mathrm{p}=0.22)$.

Table 1: Preoperative characteristics of the study population $(N=52)$

\begin{tabular}{|l|l|l|l|}
\hline & Group A (30 pts.) & Group B (22 pts.) & p \\
\hline Age & $54.3 \pm 2.6$ & $54 \pm 2.3$ & 0.22 \\
\hline Sex (male) & $17(65.38 \%)$ & $9(34.61 \%)$ & 0.001 \\
\hline Class NYHA & \multicolumn{2}{l|}{} \\
\hline
\end{tabular}




\begin{tabular}{|l|l|l|l|}
\hline IV & $8(26.6 \%)$ & $7(31.9 \%)$ & 0.9 \\
\hline III & $15(50.0 \%)$ & $10(45.5 \%)$ & 0.93 \\
\hline II & $7(23.33 \%)$ & $5(22.7 \%)$ & 0.97 \\
\hline Hypertension & $4(13.33 \%)$ & $1(4.54 \%)$ & 0.9 \\
\hline Chronic Obstructive Pulmonary Disease & $3(10.0 \%)$ & $2(9.09 \%)$ & 0.98 \\
\hline Diabetes & $2(6.66 \%)$ & $1(4.54 \%)$ & 0.001 \\
\hline Chronic Renal Insufficiency & $2(6.66 \%)$ & $1(4.54 \%)$ & 0.12 \\
\hline Atrial fibrillation & $1(3.33 \%)$ & $1(4.54 \%)$ & 0.85 \\
\hline Euro Score logistic & $4.52 \% \pm 2.18$ & $2.4 \% \pm 3.4$ & 0.001 \\
\hline
\end{tabular}

Table 2: Post-operative hospital morbidity and mortality group $A \& B(N=52)$

\begin{tabular}{|l|l|l|}
\hline \multicolumn{1}{|c|}{ Variable Number } & \multicolumn{1}{c|}{ Percentage } \\
\hline ICU stay & $48 \mathrm{~h}$ & - \\
\hline Mortality & 4 & $7.6 \%$ \\
\hline Pericardial effusion & 3 & $5.7 \%$ \\
\hline Pleural effusion & 6 & $11.5 \%$ \\
\hline Deep sternal wound infection & 2 & $3.8 \%$ \\
\hline Heart block & 3 & $5.7 \%$ \\
\hline Respiratory complication & 4 & $7.6 \%$ \\
\hline Arrhythmia & 2 & $3.8 \%$ \\
\hline Re exploration & 1 & $1.9 \%$ \\
\hline Renal impairment & 6 & $11.5 \%$ \\
\hline CVA & 2 & $3.8 \%$ \\
\hline GIT bleeding & 3 & $5.7 \%$ \\
\hline Hospital stay & $5-7$ days & \\
\hline
\end{tabular}

Prosthetic mechanical valves were used in all of with statistical difference at univariateanalisys. cases, NYHA was harvested in all cases, 15 Mean cross clamp time was 148.9 min and mean patients $(28.8 \%)$ were in class IV, $25(48.1 \%) \quad$ CPB was $187 \mathrm{~min}$, The overall mortality rate was were in class III, the remaining $12(23.1 \%)$ were $7.6 \%$ (4 patients group A \& B), one of them in class II. No difference was evident in could not be weaned from the bypass, the second proportion of NYHA class comparing the two one was CVA that required prolonged respiratory groups of study population. In-hospital death support, the third one was cardiac tamponade, occurred in 4 patients $(7.67 \%), 3(5.75 \%)$ and the last one was multi-organ failure [Table patients in group A and $1(1.92 \%)$ in group B 2].

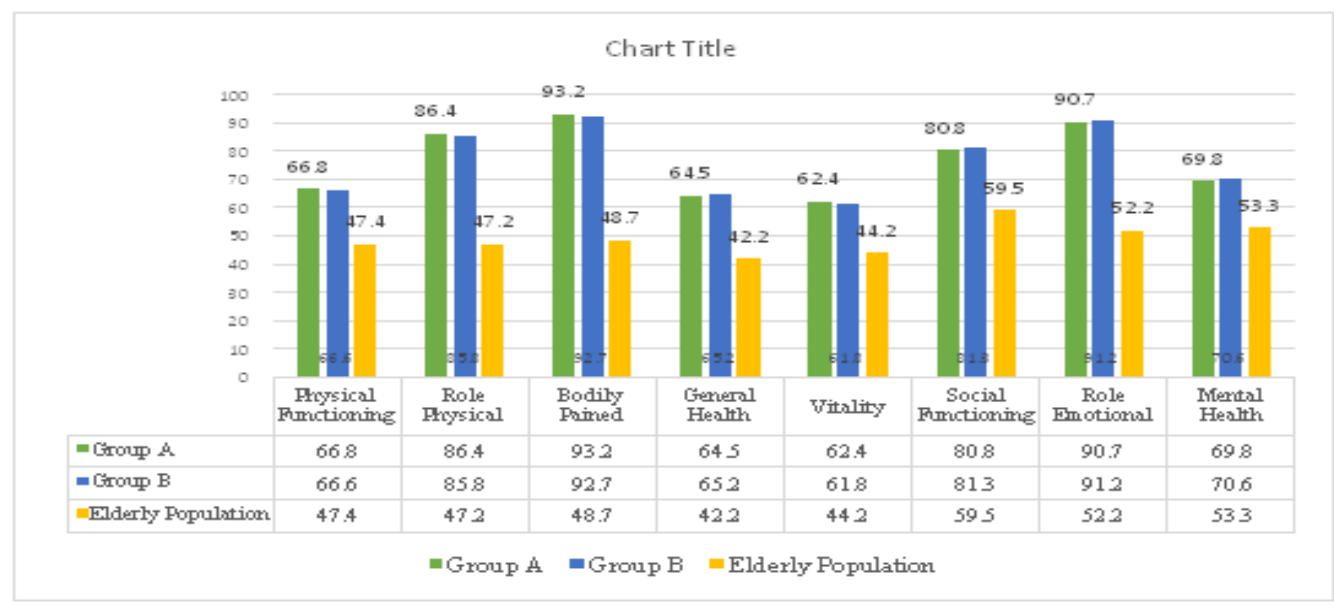

Figure1: SF-36 score obtained in the 8 domains of the questionnaire in the Group A, in the group $B$ and in the patients an age and sex-matched population.

All survivors answered the questionnaire, and there was no statistical difference in the scores obtained in the two groups of the study

population evaluating the eight domains of the test. When compared with the mean scores of the general Bangladeshi population matched for age and sex, significantly higher scores were reached by the two groups of the study population, with a $\mathrm{p}$ value of $<0.001$ in all domains. The scores obtained in the various domains for Group A, Group B and the general Bangladeshi populations of Elderly were reported [Figure 3].Findings of our study confirmed that short term mortality and morbidity are not significantly different when CABG is associated to AVR in elderly patients 
suffering of severe calcified aortic valve stenosis and obstructive coronary disease. In order to extend the investigation to short term quality of life, the SF-36 test was applied in both groups of patients. Group A and Group B showed similar scores in QOL that resulted better of age and gender matched population.

\section{DISCUSSION}

The increased life expectancy of the Western population in the last decades [9], associated with the improvements in surgical standards and postoperative care, has progressively expanded the age criteria of operability in cardiac surgery [10]. As a consequence, the number of elderly patients undergoing heart valve replacement has been increasing, as well as their short-term survival. In particular it has been rising the number of elderly requiring AVR for severe calcific aortic valve stenosis, which is a typical disease of the older age. The growing number of elderly referring to cardiac surgical procedures has increased the attention on the outcomes in this subset of patients and on the prediction of short term survival. When coronary artery obstructive disease is associated to severe aortic valve calcific stenosis in the elderly patients, CABG has to be combined to AVR. Many clinical series investigating determinants of early mortality following AVR, identified associated CABG as independent predictor [11, 12].The $4^{\text {th }}$ European Association for Cardiothoracic Surgery Adult Cardiac Surgery 2010 database reports that overall mortality for isolated valve surgery is $3.7 \%$ while for CABG combined with valve procedures it increases to $6.2 \%$ [13]. Also in our series the association of CABG to AVR demonstrated to increase hospital mortality $(15.2 \%$ vs $7.8 \%)$ and univariate analysis revealed CABG as a predictor of early death. At the same time CABG associated to AVR improves short term survival with acceptable morbidity and mortality in elderly patients [12].This data is confirmed by several reports: on the arena of short term survival, Akins et al. Reported the survival of patient following $\mathrm{CABG}$ is essentially equivalent to that of age and gender matched cohorts from the general population up to 5 years after surgery [14]. Sergeant and associated demonstrated that the actuarial survival of elderly coronary artery bypass patients came actually be better than that predicted for the general population out to 10 years, whereas survival of the young coronary by-pass patients is poorer than a comparable cohort from the general population [15]. Findings of our study confirmed that short term mortality and morbidity are not significantly different when CABG is associated to AVR in elderly patients suffering of severe calcified aortic valve stenosis and obstructive coronary disease. In order to extend the investigation to short term quality of life, the SF-36 test was applied in both groups of patients. Group A and Group B showed similar scores in QOL that resulted better of age and gender matched population. The increased life expectancy results in a growing necessity to maintain maximum functioning and independent lifestyle. Healthrelated QOL is a multidimensional concept based on the patient's perception of his or her health and integrates not only physical functioning but also psychologic status and social dimensions. Standardized questionnaires, especially those self-completed by patients, are a practical, efficacious, and inexpensive method of collecting data. There is a growing interest in the use of health status to evaluate clinical strategies, and because improvement in QOL is considered to be one of the principal goals of valve surgery [16], methods of QOL assessment are increasingly adopted in the clinical research in this field. From reports on postoperative QOL, patients deciding among treatment options may value information about the change in QOL that they can expect after valve surgery. Therefore, QOL needs to be assessed in large and well-defined patient subsets, and it is particularly important to evaluate QOL in elderly patients, who have a higher prevalence of comorbidity, a more severe surgical stress, and a higher risk of postoperative complications, all factors that may hinder improvement in QOL. Although numerous methods exist for evaluating QOL of patients [17], the validated SF-36 questionnaire [8] is comprehensive yet concise, can be completed in 10 to 15 minutes, and can be administered in person, by phone, or by mail, even in elderly patients [7]. Investigators focusing on short-term outcomes after AVR in octogenarians have reported a positive impact on QOL [18]. Operative mortality ranging from $5.5 \%$ to $7.5 \%$ for AVRCABG procedures over the last 10 years [28]. Over the last ten years, the Society of Thoracic Surgeons National Cardiac Database has described a fair even though continuously higher operative mortality rate in patients undergoing AVR with CABG (4.5\%) versus isolated AVR (3\%) [29]. about $11.5 \%$ of patients developed symptomatic pleural effusion $(\mathrm{PE})$ in the first month after surgery that required re-admission and intervention. 
Approximately $10 \%$ of patients post-CABG develop PE that occupies more than one-four of the hemithorax. Most CABG related PEs are left sided [30]. Anticoagulants (unfractionated heparin, low-molecular-weight heparin, and warfarin), clopidogrel, anti-arrhythmic agents, and diuretic agents have also been associated with PE development, which may be partly due to the underlying conditions for which such medications are prescribed. In this study, all the patients were taking acetylsalicylic acid both preoperatively and postoperatively [31]. In this study there are a lot of causes that can be blamed for the pleural effusion, long surgery, $\mathrm{CPB}$, use anti-platelet and anticoagulation, routine use of LIMA. In this study, there was $5.7 \%$ pericardial effusion that necessitated readmission. Sundt and colleagues described postoperative SF-36 scores in AVR patients aged older than 50 years that were comparable with those of the general elderly population [19]. In the present study, we obtained in seven of the eight domains of the test significantly higher scores than the mean general Bangladeshi population matched for age and sex. When interpreting this result, it should be considered that more than $70 \%$ of the patients in our study population were in NYHA functional class III to IV before the operation, so a high percentage of our patients experienced, for a various period of time, a moderate to severe limitation to their daily activity. Symptom relief and the return to previous lifestyle can probably increase the perception of a patient's own health status. Similarly, the Bangladeshi general population scores were lower than in our study population because the healthy elderly are prone to compare their current physical and psychological performances with their youth, with a perceived difference caused by the effects of the aging process itself. Other authors in series of AVR [20] found similar differences between the previously operated on elderly and the age-matched control population, in particular for what concerns the social functioning and emotional domains. In this study it was mostly due to antiplatelet and anticoagulant drugs as well as stress ulcer due to this type of surgery. There are several limitations to this study. These include the retrospective nature of this study, poor compliance of patients, single-center experience and lastly small sample size.

\section{CONCLUSION}

Survivors did not show differences in short-term outcome and quality of life. Overall, the risk factors for short-term mortality following valve replacement and CABG surgery appear to be relatively consistent. However, clinicians should be aware of the importance of preoperative functional status as a unique predictor of mortality following valve surgery.

\section{REFERENCES}

[1] Melby SJ, Zierer A, Kaiser SP, et al: Aortic valve replacement in octogenarians: risk factors for early and late mortality. Ann ThoracSurg 2007, 83:1651-1656.

[2] Sedrakyan A, Vaccarino V, Paltiel AD, et al: Age does not limit quality of life improvement in cardiac valve surgery. J Am CollCardiol2003, 42:1208-1214.

[3] Vicchio M, De Santo LS, Della Corte A, De Feo M, Provenzano R, Miraglia M, Scardone M, Cotrufo M: Aortic valve replacement with 19-mm bileafletprostheses in the elderly: left ventricular mass regression and quality of life. $\mathbf{J}$ Heart Valve Dis 2008, 17:216-21.

[4] Vicchio M, Della Corte A, De Feo M, Santarpino G, De Santo LS, Romano G, Caianiello G, Scardone M, Cotrufo M: Quality of life after implantation of bileaflet prostheses in elderly patients: an anticoagulation work group experience. Ann ThoracSurg 2007, 84:459-65.

[5] Vicchio M, Della Corte A, De Santo LS, De Feo M, Caianiello G, Scardone M, Cotrufo M: Prosthesis-patient mismatch in the elderly: survival, ventricular mass regression, and quality of life. Ann ThoracSurg2008, 86:1791-7.

[6] Henry Edmunds L, Clark ERichard, Cohn HLawrence, Grunkemeier LGary, Craig Miller D, WeiselDRichard: Guidelines for Reporting Morbidity and Mortality After Cardiac Valvular Operations. Ann ThoracSurg1996, 62:932-935.

[7] Lyons RA, Perry HM, Littlepage BN: Evidence for the validity of the short form 36 questionnaire (SF-36) in an elderly population. Age Ageing 1994, 23:182-4.

[8] Apolone G, Mosconi P: The Bangladeshi SF-36 Health Survey: translation, validation and norming. J ClinEpidemiol 1998, 51:1025-36.

[9] Parant A: Demographic trends in Europe. Futuribles 1993, 175:43-55.

[10] Kolh P, Kerzmann A, Lahaye L, Gerard P, Limet R: Cardiac Surgery in octogenarians. Eur Heart J 2001, 22:1235-1243.

[11] Kasimir MT, Bialy J, Moidl R, Simon-Kupilik N, Mittlböck M, Hiesmayr M, Wolner E, Simon P: EuroSCORE predicts mid-term outcome after combined valve and coronary bypass surgery. J Heart Valve Dis 2004, 13:439-43.

[12] Kurlansky PA, Williams DB, Traad EA, Carrillo RG, Schor JS, Zucker M, Ebra G: The influence of coronary artery disease on quality of life after mechanical valve replacement. J Heart Valve Dis 2004, 13:260-71. 
[13] Bridgewater B, Kinsman R, Walton P, Gummert J, Kappetein AP: The 4th European Association for Cardio-Thoracic Surgery adult cardiac surgery database report. Interact CardiovascThoracSurg 2011, 12:4-5.

[14] Akins CW, Hilgenberg AD, Vlahakes GJ, MacGillivray TE, Torchiana DF, Madsen JC: Results of bioprosthetic versus mechanical aortic valve replacement performed with concomitant coronary artery bypass grafting. Ann ThoracSurg 2002, 74:1098-106.

[15] Sergeant P, Wouters P, Meyns B, Bert C, Van Hemelrijck J, Bogaerts C, Sergeant G, Slabbaert K: OPCAB versus early mortality and morbidity: an issue between clinical relevance and statistical significance. Eur $\mathrm{J}$ CardiothoracSurg 2004, 25:779-85.

[16] Bonow RO, Carabello B, de Leon Ac, Edmunds LH, Fedderly BJ, Freed MD: ACC/AHA guidelines for the management of patients with valvular heart disease: a report of the American College of Cardiology/American Heart Association Task Force on Pratice Guidelines. J Am CollCardiol1998, 32:1486-1588.

[17] Walter P, Mohan R, Amsel BJ: Quality of life after heart valve replacement. J Heart Valve Dis 1992, 1:34-41.

[18] Vicchio M, Della Corte A, De Santo LS, De Feo M, Caianiello G, Scardone M, Cotrufo M: Tissue versus mechanical prostheses: quality of life in octogenarians. Ann ThoracSurg 2008, $85: 1290-5$.

[19] Sundt TM, Bailey MS, Moon MR, Mendeloff EN, Huddleston CB, Pasque MK, Barner HB, Gay WA Jr: Quality of life after aortic valve replacement at the age of $>80$ years. Circulation 2000, 102(19 Suppl 3): III 70-4.

[20] Pupello DF, Bessone LN, Lopez E, Brock CJ, Alkire JM, Izzo GE, Sanabria G, and Sims PD, Ebra G: Short-term results of the bioprostheses in the elderly patients: impact on quality of life. Ann ThoracSurg 2001, 71:S244-8.

[21] World health rankings, live shorter live better [internet].2012 [cited 2012 Nov 10]. Available from: http://www.worldlifeexpectency.com/ country-health-profile/Bangladesh.

[22] Gehlot A, Mullany CJ, Ilstrup D, Schaff H, Orszulak T, Morris J, et al. Aortic valve replacement in patients aged eighty years and older: early and short-term results. J ThoracCardiovasc Surg. 1996; 111:1026-36.

[23] Kohl P, Kerzmann A, Lahaye L, Gerard P, Limet R. Cardiac surgery in octogenariansperioperative outcome and short-term results. Eur Heart J. 2001; 22:1235-43.

[24] Kohl P, Kerzmann A, Honore C, Comte L, Limet R. Aortic valve surgery in octogenarians: predictive factors for operative and mid-term results. Eur J Cardio-thorac Surg. 2007; 31:600-6.

[25] Melby SJ, Zierer A, Kaiser SP, Guthrie T, Keune J, Schuessler R, et al. Aortic valve replacement in octogenarians: risk factors for early and late mortality. Ann Thorac Surg. 2007; 83:1651-7.

[26] Alexander KP, Anstrom KJ, Muhlbaier LH, Grosswald R, Smith P, Jones R, et al. Outcomes of cardiac surgery in patients $>$ or $=$ 80 years: results from the National Cardiovascular Network. J Am CollCardiol. 2000; 35:731-8.

[27] Authors/Task Force Members, Vahanian A, Alfieri O, Andreotti F, Antunes MJ, BaronEsquivias G, et al. Guidelines on the management of valvular heart disease (version 2012): The Joint Task Force on the Management of Valvular Heart Disease of the European Society of Cardiology (ESC) and the European Association for Cardio-Thoracic Surgery (EACTS). Eur J Cardiothorac Surg. 2012; 42(4):S1-44. doi:10.1093/ejcts/ezs455.

[28] Adult Cardiac Database Executive Summary. Available at: http://www.sts.org/documents/ pdf/Spring2005 STS-ExecutiveSummary.pdf. [Accessed 19 August 2005].

[29] Society of Thoracic Surgeons Adult Cardiac Surgery Database Executive Sum-mary. Available at: http://www.sts.org/sts-nationaldatabase/ database - managers/ executivesummaries. [Accessed 24 March 2014].

[30] Light RW, Rogers JT, Moyers JP, Lee YG, Rodriguez RM, Alford Jr WC, et al.Prevalence and clinical course of pleural effusions at 30 days after coronaryartery and cardiac surgery. Am J RespirCrit Care Med 2002; 166(12): $1567 \mathrm{e} 71$.

[31] Labidi M, Baillot R, Dionne B, Lacasse Y, Maltais F, Boulet LP. Pleural effusionsfollowing cardiac surgery: prevalnce, risk factors, and clinical features. Chest2009; 136(6):1604e11.

Citation: Chowdhury MG, Hoque KZ, Hossain M, BaraiLC, Saha MK, Jamil AM. Atrioventricular Block in Acute Coronary Syndromes. ARC Journal of Cardiology. 2020; 6(2): 07-13. Doi:doi.org/ 10.20431/2455-5991. 0602002.

Copyright: (C) 2020 Authors. This is an open-access article distributed under the terms of the Creative Commons Attribution License, which permits unrestricted use, distribution, and reproduction in any medium, provided the original author and source are credited. 